\title{
A REVIEW OF MULTI-HAZARD RISK ASSESSMENT (MHRA) USING 4D DYNAMIC MODELS
}

\author{
T. Bibi*, A. Abdul Rahman \\ Department of Geoinformation, Faculty of Geoinformation and Real Estate, Universiti Teknologi Malaysia, UTM Skudai 81310, \\ Johor, Malaysia - tehmina_khan79pk@ hotmail.com, alias.fksg@gmail.com
}

KEY WORDS: Multi natural hazards, Risk assessment, Three dimensional, Dynamic phenomenon's, 4d dynamic models.

\begin{abstract}
:
This paper reviews the 4D dynamic models for multi natural hazard risk assessment. It is important to review the characteristic of the different dynamic models and to choose the most suitable model for certain application. The characteristic of the different 4D dynamic models are based on several main aspects (e.g. space, time, event or phenomenon etc.). The most suitable 4D dynamic model depends on the type of application it is used for. There is no single 4D Dynamic model suitable for all types of application. Therefore, it is very important to define the requirements of the 4D Dynamic model. The main context of this paper is spatio temporal modelling for multi hazards.
\end{abstract}

\section{INTRODUCTION}

Natural Hazards are the occurrences, events or phenomenon that happens naturally. It includes numerous different physical phenomenons, i.e. earthquakes, tsunamis, landslides, floods, volcanic eruptions, severe storms, tornadoes, and many more (Petley, 2009). These events are sudden and unexpected and cause the disruption in the balance of topography and environment. The conversion of a natural hazard to a disaster can be understood in scientific terms (e.g. geological or geophysical), but the physical infrastructure and sociological aspects also play key roles (Koch, 2000). Disasters can be considered as based on the probability or relative frequency of hazardous events and the impacts of these events depend on their intensity or magnitude.

Now days the world is confronted with a rapidly growing impact of natural disasters and unexpected increasing vulnerability to society combined with an increase in hazardous events. Handmer et al, (2012) mentioned that developing countries are more vulnerable physically and economically to disasters because of low resilience and dependence on natural capital and disaster-sensitive activities. Kim (2012) admitted that most poor communities are more exposed to natural disasters because of multiple reasons. In the major part of the world, more than one hazard may act in the same time frame, leading to different risks. Individual investigations of single hazard only might mislead to judge the general natural risks for that area. The multi-hazard risk approach is not only valuable to get an overview of all risks but have also a high significance for planning effective counter measures. (Bell et al, 2004). The term "multi-hazards" refers to all expected and related hazards, and their interactions, in a given spatial region over a temporal period (J. C. Gill and B. D. Malamud, 2014). It is used in most cases closely related to the objective of risk reduction (Melanie S. Kappes et al, 2012).

Hazards can be single, sequential or combined in their origin and effects (Cees J. van Westen, 2012) but it particularly concentrated in certain geographical regions. For example, the active movements of continental slope margins in the Pacific generate earthquakes and volcanic eruptions. On the other hand the tropical and extra-tropical regions are most likely to originate typhoons because of the temporal changes in sea surface temperature (Chan and Liu, 2004). The uneven geographical distributions of natural hazards and its frequency of reoccurrence is a good example of time and space utilization. Hazard has time-space geography, involving the probabilities of significant magnitude to cause potential damage. Burton et al, (1993) introduced six parameters as the spatio-temporal characteristic of hazard, i.e. frequency, duration, spatial dispersion, speed of onset, areal extent and temporal spacing. If the time and space both co-ordinates in a particular hazardous situation it may cause a higher risk..

The real world is three dimensional and all phenomenon's' acting on it cannot be properly understandable without taking in to account the third dimension. The more suitable tool for earth science applications a GIS can provide is a 3D modelling capability, that is to say, a 3D GIS (Rahman. et al. 2007). A 3D GIS assume to provide the same functions as 2D GIS (Zlatanova et al, 2002) but unfortunately, it is considered as visualization ability of the software. All the natural calamities existing on the earth surface have dynamic behaviour. To study their behaviour, vulnerability and risk to land and people needs to incorporate the third dimension of real world. Several studies are conducted on the use of 3D geographic information for modelling the hazards and corresponding environments. Zlatanova et al, (2007) proposed an emergency response framework. This study evaluates the multi-risk emergency situation response systems from a 3D spatial information perspective, and they proposed a system architecture which covers data management and communication for hazard prone areas. All above studies, however, have not provided a detailed methodology for the risk assessment of multiple natural hazards with 3D GIS.

\section{4D DYNAMIC MODELS}

Natural disasters are dynamic in nature. The basic purpose of Modelling or simulation of dynamic phenomena is to help out 
decision makers to have a better understanding with the nature of disaster in terms of risk assessment and damage reduction. There are a number of publicly developed tools exist (Central America Probabilistic Risk Assessment - CAPRA, Riskscape in New Zealand, HAZUS-MH in the United States), allowing for some comparability between hazards However, these models neither examine the temporal, spatial or causal relationships that frequently occur between hazards, nor taking into account the dynamic nature of hazards.

Different hazards have different impact areas and return periods: for instance, temporal and spatial scales for earthquakes differ from those for landslides or floods, as does the type of data that is required for parameterisation and calibration of risk models. Risk assessment for an area exposed to multiple hazards requires solutions to compare the risks in a probabilistic way and plan accordingly, whenever possible. Risk assessment models that take into account several hazards at the same time, and thus include a certain degree of harmonisation, exist both in the public and the private sector, but there are no international standards for harmonisation that could allow some interoperability between models (OECD, 2012).

Several spatio-temporal data models are recommended in the literature. Armstrong, (1988) introduced the snapshot model. Temporal information has also been incorporated into this spatial data model by time stamping layers. It was one of the simplest spatio-temporal data model and was not able to support complex queries. The space-time composite (STC) data model was suggested by Langran et al, (1988). This model was having sufficient support for most types of spatio-temporal queries but the Problems appears in representing phenomena like front lines, re-ignition, and spotting. There was lack of direct mappings from GIS data to model input hampers and GIS abilities of spatio-temporal analysis, such as calculating periodicity, rate of movement, and process in STC model. To solve these issues another simple approach was tagged that every object have a pair of timestamps, (Hunt \& Williamson, 1990) one for the time of creation and one for the time of cessation. The drawback of this model was that it was not possible to attain direct information of what happened and why. In other words its ability to show change was nil. Additional attempts have been made to provide such direct mappings by event-based data model (Peuquet and Duan, 1995 ), also called as event oriented spatio-temporal data model (ESTDM.) An event component shows changes to a predefined location (a raster cell) at a specific point in time. The ESTDM has shown that it is capable of supporting both spatial and temporal queries, and does so efficiently. However, the transformation of the ESTDM to a vector based system requires a substantial redesign of event components. Mechanisms are needed to permit event components to keep track of their predefined units and locations.

Yuan, (1994) described a three-domain model for spatiotemporal modelling. The key advantage of the three domain model was that there were no pre-defined data schemata; the model was dynamically linked to relevant objects from the three domains to represent a geographic entity or concept. The model was a revolution in the development of spatio-temporal databases, because it was the first successful attempt to record individual descriptive characteristics of dynamic objects.

The history graph model was developed by Renolen, (1996) to identify all kinds of temporal behaviour and to manage both objects and events. It can be thought of as an extension to the event-oriented way of thinking. The advantage of this model was that temporal relationships could be derived directly and the time can be modelled both either discrete or in a continuous way as well as absolute or relative. This model manages both events and objects in their data sets. Later the spatio-temporal entity-relationship (STER) model by Tryfona, (1997), Objectrelationship (OR) model by Claramunt et al, (1998) and Moving object data model by Erwig et al. (1999) were introduced to cope with the shortcoming of other models.

\section{CONCLUSION}

The multi-hazard risk assessment is an emerging field of study in geosciences. It is gaining importance because of rapidly growing hazardous events (Handmer et al, 2012). The literature review reveals that there is some conceptual framework available for multi-hazard risk assessment but still there are no international standards for harmonisation that could allow some interoperability between different models for risk assessment of multi-hazard (OECD, 2012).

Until now the field of 4D dynamic modelling is progressing and the all above mention models are facing the changes with new ideas of researches but still there is no authentic model which can efficiently model the 4D risk assessment of multi-hazard. However it is possible to combine two or more models to get accurate results for dynamic multi-hazard modelling.

Based on reviews of 4D dynamic modelling, the most suitable model is event based data model (Peuquet and Duan, 1995) for multi-hazard risk modelling because it can model multiple events at a time. With the help of this model change can be detected and monitoring scenario for future may be developed.

\section{REFERENCES}

Abdul-Rahman, A. and Pilouk, M. Spatial Data Modeling for 3D GIS. Springer 2008 Berlin Heidelberg New York. ISBN 978-3-540-74I66-4.

Armstrong, M. P., 1988, Temporality in spatial databases. Proceedings: GIS/LIS'88, 2:880-889.

Bell, R. \& T. Glade (2004): Multi-hazard analysis in natural risk assessments. Proceedings of the International Conference on Computer Simulation in Risk Analysis and Hazard Mitigation (RISK ANALYSIS 2004), Rhodes, Greece, 197206.

Billen R., S. Zlatanova, P. Mathonet and F. Boniver, (2002). The Dimensional Model: a framework to distinguish spatial relationships, in: Advances in Spatial Data handling, D.Richardson, P.van Oosterom (Eds.), Springer, pp. 285-298.

Burton, I., Kates, R. W., and White, G. F. 1993,. The Environment as Hazard, Second ed., The Guilford Press, New York, 290 pp.,

Chan, J. C. L, and S. L. Liu. 2004: Global warming and western North Pacific typhoon activity from an observational perspective. J. Climate: 17. 4590-4602. 
C. J. Westen, Remote Sensing and GIS for Natural Hazards Assessment and Disaster Risk Management, Dehradun, India, pp. 307-375, May 2012.

Claramunt, C, Parent, C, Spaccapietra, S and Theriault, M, 1998, Database modeling for environmental and land use changes. Geographical Information and Planning. Berlin: Springer, ch. 20.

Erwig, M, Guting, RH, Schneider, $\mathrm{M}$ and Vazirgiannis, M, 1999, Spatio-temporal data types: an approach to modeling and querying moving objects in databases. GeoInformatica 3(3), 265-291.

Gill, J., Malamud, B. (2014) Reviewing and visualizing the interactions of natural hazards. Reviews of Geophysics 52 doi: 10.1002/2013RG000445

Handmer, J., et al, (2012). Changes in impacts of climate extremes: human systems and ecosystems. In: Managing the Risks of Extreme Events and Disasters to Advance Climate Change Adaptation. A Special Report of the Intergovernmental Panel on Climate Change (IPCC). Cambridge University Press, Cambridge, UK, and New York, NY, USA, pp. 231-290.

Hunter, G.J and Williamson, I.P, 1990 The development of a historical digital cadastral database. International Journal of Geographic Information Systems 4(2).

Kappes M., Keiler M, von Elverfeldt K, Glade T (2012) Challenges of analyzing multi-hazard risk: a review. Nat Hazards 64(2):1925-1958.

Koch, M. 2000. "Natural Hazards and Disasters: Origins, Risks, Mitigation and Prediction." Paper presented at the International Symposium on River Flood Defence, Kassel, Germany.

Kim, N. 2012. "How Much More Exposed are the Poor to Natural Disasters? Global and Regional Measurement" Disasters 36 (2): 195-211.

Langran, G. and Chrisman, N, R., 1988, A framework for temporal geographic information. Cartographica, 25(3):1-14

OECD, 2012. Global Modelling of Natural Hazard Risks: Enhancing Existing Capabilities to Address New Challenges.

Peuquet, D and Wentz, E, 1994, An approach for time-based spatial analysis of spatio-temporal data. Advances in GIS Research, Proceedings 1, 489-504.

Renolen, A, 1996, History graphs: conceptual modeling of spatio-temporal data. GIS Frontiers in Business and Science, vol. 2,International Cartographic Association, Brno, Czech Republic.

Smith, K., and D. N. Petley (2009), Environmental Hazards: Assessing Risk and Reducing Disaster, Routledge, New York.

Tryfona, N, 1997, Modeling Phenomena in Spatiotemporal Databases: Desiderata and Solutions. Department of Computer Science, Aalborg University, Denmark.

Yuan, M, 1994, Wildfire conceptual modeling for building GIS space-time models. Proceedings of the GIS/LIS '94, 860-869.
Zlatanova, S., D. Holweg and M. Stratakis, (2007) Framework for multi-risk emergency response, in: Tao\&Li (Eds.) Advances in Mobile Mapping Technology, Taylor\&Francis, London, ISPRS Book Series, pp. 159-171

Zlatanova, S., A.A. Rahman and M.Pilouk, 2002, Trends in 3D GIS development, in: Journal of Geospatial Engineering, Vol.4, No.2, pp. 1-10 